\title{
Color Variation from Vehicle in The Road and Its Environment Through Subtle Motion Study Case
}

\author{
Septian Enggar Sukmana*1, Farah Zakiyah Rahmanti ${ }^{2}$ \\ Universitas Dian Nuswantoro / Informatics Department, Jalan Imam Bonjol 207 Semarang, \\ (+6224) 3517261/(+6224) 3569684 \\ E-mail : septian.enggar@dsn.dinus.ac.id*1, farah.zakiyah@dsn.dinus.ac.id ${ }^{2}$ \\ *Corresponding author
}

\begin{abstract}
Road accident has been serious case in Indonesia, the big number of the cases is not decreasing for six years. Many ways have been done, one of example is exploiting smart camera or CCTV to observe mocement estimation explicitly or implicitly. One problem is when explicitbased technique is applied, the computation process would take more resource. Implicit-based technique like exploitting processing-based frequency domain must be tried to make a better study and produce more knowledge in this study field. Color magnification can helpful information to support better movement estimation. This eulerian-based technique may be the one useful method to help this study. This paper implements eluerian video magnification to get color magnification on road as observed environment. This technique produces unexpected result that unknown black color appears, it still ambiguous because some scene can be described as black color object magnification result and another is shocking camera effect so that the technique is difficult to obtain color magnfication result. PSNR results quite better value because in spite of color magnification result distraction, the scenery of the road is not covered fully. SSIM shows that some mapping in each video data can not results same pattern, it is suspicious that SSIM mapping is affected by this color magnification result.
\end{abstract}

Keywords - movement vehicle estimation, eulerian video magnification, subtle motion

\section{INTRODUCTION}

Based on 2010-2016 road accidental by Kementerian Perhubungan Republik Indonesia, human factor has been a top rank in cause of accident [1]. In the latest trimester, the number of accident has not been decreased from 20,000 cases with 5,000 cases makes serious death victims [2]. It shows that human factor is a serious matter in many forms like less attetion while driving or unhealthy body physical when driving [3]. Bad positioning by human when driving on the road is also a factor to make an accident of vehicle. An abnormal movement of vehicle can be described as a sign of this kind accident. This abnormal movement can be recognized by another driver by some strange behaviours. This behavior can threat other people safety and damage between each vehicle can not be avoided in this situation [4].

A caution of an abnormal vehicle movement on the road can be reflected by human itself easily, but for smart vehicle system needs special hardware and software technique. Camera sensor is one of main component in this system, this component needs special computational feature. One of the latest feature is developed by Hui et.al [5] by focusing vehicles which are spotted by this camera and detecting when collition between vehicle happens. 
Another collision detection feature has been developed by Bernini et.al [6] using computer vision technique.

Main thing in development of warning detection system is information of this vehicle movement. It can be identified by system by two things such explicit or implicit movement estimation [7]. Explicit movement estimation costs more computation resource so it warns to data processing of vehicle movement about more times would take in that process. Implicit movement estimation can be solution because spatio-temporal processing in video data does not burden movement estimation requirement that must be accurate. It has an advantage in observing a phenomenon that can not be seen by common eye visual or it can be called subtle motion. Wang et.al [8] and Liu et.al [9] implement Lagrangian series processing to observe the subtle motion, beside Wu et.al [7] and Wadhwa et.al [10] choose Eulerian because efficient computation.

Color magnification is a feature in subtle magnification in Wu et.al [7]. Because of this, implementing subtle motion technique can help color variation that happens on roadway via vehicle censor camera. Study about color that happens on the road is important because its color information can be observed as vehicle movement, if a vehicle object which is has some domination color walks, the result of color magnification of its vehicle can be seen where this vehicle moves to. This paper presents about discovery in implementing color manification on the road. The camera has ben placed to the vehicle to get data then color magnification technique via Eulerian Video magnification [7] is applied. The dinamic scene can be a challenge in this activity, some unexpexted result may comes. This research is very contributive to develop detection collision warning system in smart vehicle with another perspective using processingbased frequency domain.

\section{RESEARCH METHOD}

Color magnification is performed on the data. The data is retrieved from video recording activity which is taken in the street, this scheme starts from placing a camera in the vehicle then video recording is activated when the vehicle starts to walk in the road. The retrieved data which is recorded and used to this activity is $720 \mathrm{p} \mathrm{HD}$, it is still raw so the color magnification technique would be implemented after this. The color magnification is the technique which follows eulerian video magnification, this starts from decomposition on each frame spatially, then temporal processing is applied with the same filter band to all bands and then added to original signal to get output video (Fig. 1).

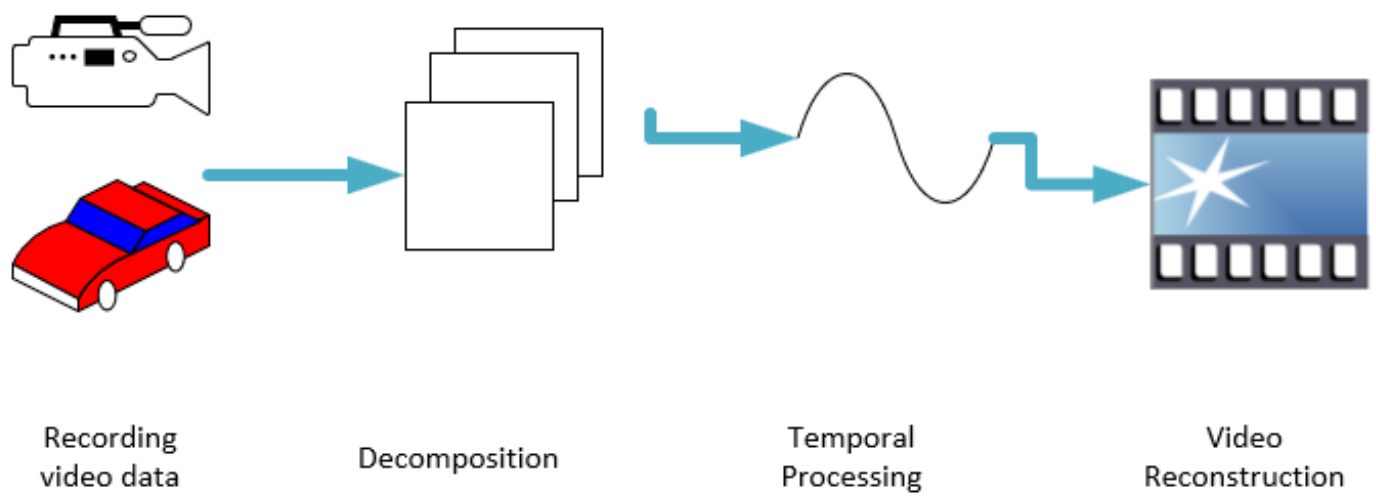

Figure 1. Basic Methodology's step 
The same $\alpha$ to performs color magnification technique is used in each spatial band. It is a must because different spatial frequency bands have to be gotten by decomposition result of video sequence. Signal synthesization can be reached by temporal processing based on firstorder Taylor series expansions

$I(x, t)=f(x+(1+\propto) \delta(t))$

where $I(x, t)$ is image intensity at position $x$ and time $t$.

The impact of first-order Taylor expansion, some modifications in time $t$ about $x$ happens

$I^{\prime}(x, t)=f(x)+\delta(t) \frac{\delta f(x)}{\partial x}$

Image intensity has changed because of broadband temporal bandpass filter $B(x, t)$

$B(x, t)=\delta(t) \frac{\delta f(x)}{\partial x}$

Not only broadband temporal bandpass filter $B(x, t)$, the amplification of bandpass signal also intervens image intensity

$I^{\prime}(x, t)=I(x, t)+\propto B(x, t)$

Because of combination between (2), (3), and (4), output will be created in the form of $I^{\prime}(x, t)$ approximation to $f(x+(1+\propto) \delta(t))$.

$I^{\prime}(x, t) \approx f(x)+(1+\propto) \delta(t) \frac{\delta f(x)}{\partial x}$

The value of processed signal $I^{\prime}(x, t)$ must be equal to magnified function. It is important because there is some failure in image function because of Taylor approximation.

$f(x)+(1+\propto) \delta(t) \frac{\delta f(x)}{\partial x} \approx f(x+(1+\propto) \delta(t))(6)$

$f(x)=\cos \omega x$ is for spatial frequency $\omega$ and $\beta=1+\alpha$ for (7) then use addition law for cosines (8).

$\cos (\omega x)-\beta \omega \delta(t) \sin (\omega x) \approx \cos (\omega x+\beta \omega \delta(t))(7)$

$\cos (\omega x)-\beta \omega \delta(t) \sin (\omega x)=\cos (\omega x) \cos (\beta \omega \delta(t))-\sin (\omega x) \sin (\beta \omega \delta(t))$ (8)

After this color magnification technique is applied to each decomposition result in each frame, the reconstruction of video will be performed. All decomposition results will be assembled to be a single video again with color magnification result.

\section{RESULTS AND DISCUSSION}

Video processing is performed in very slow speed because to get the best result in motion magnification, the almost still object movement condition is a must. This experiment was conducted with parameter $\alpha=20$ for motion amplification. Figure 2 shows movement magnification results based by three samples condition, it shows that black appearence tells that camera is in shocking condition by different result between figure 2(a) and 2(b). More black appearance comes, it can be described as tha camera has a big amount of shocking (figure 2(a)), on contrary the less black appearance means less shocking in camera (figure 2(b)). 


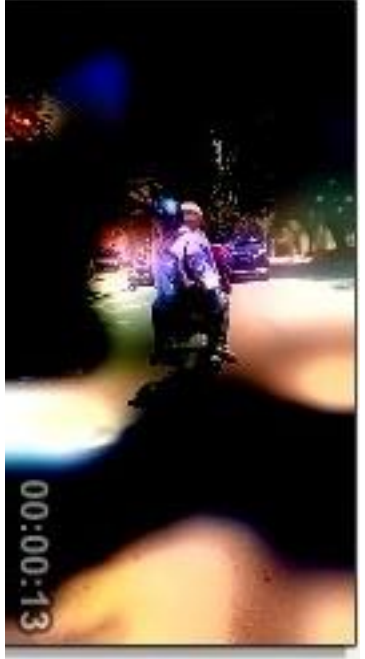

(a)

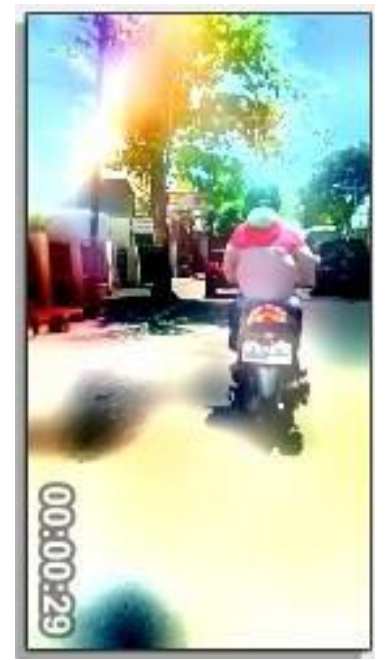

(b)

Figure 2. Camera condition: a) more shocking; b) less shocking.

The black appearance is defined as shocking cindition of camera because when camera is shocked, the black appearance more coming. Maybe the big question is what black appearance is. The black appearance can be described as magnification of color of each object in the environment (Figure 2). Actually, this phenomenon is also implemented in each color. But, the black one is unique, it comes more often than another color.

To get more detail about this black color appearance, some samples are examined. Figure 3 shows some samples, each of sample represents different condition of black appearance form. Figure 3 (d) is raw version of figure (a), by comparing those two frames a strange phenomenon is discovered and marked by red circle area between those frames, it is clearly known that in the red circle area between figure 3 (d) and figure 3 (a) there are no real black object color in figure 3 (d) but in figure 3 (a) the black appearance comes. It seems that grey color of the road is magnificated but in the black color, it proves that color composition of the road contains more black color than white color. Not all phomenon is implemented on the road. Based on blue circle, it comes bright appearance, it seems that light color of sun is more known by this method than another color or energy of light of sun is more powerful than another color energy. More dominant of light color of sun can be observed on figure xxx (b) which is the raw version is on figure $3(\mathrm{e})$, by observing this kind of domination phenomena, more color is extracted. This is also decribed in figure 3 (c) with figure 3 (f) as raw image, if black appearance and color of sun is composed more balance, the color magnification is seen more clearly.

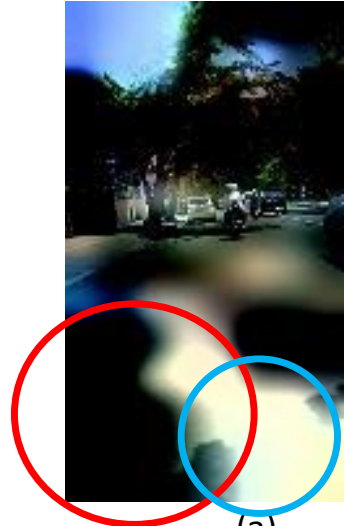

(a)

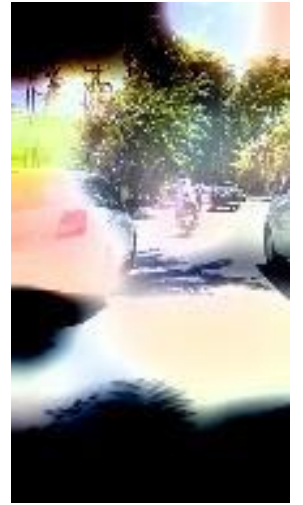

(b)

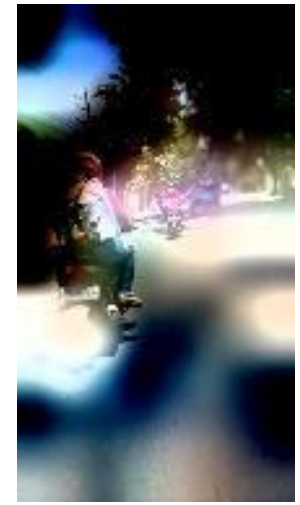

(c) 


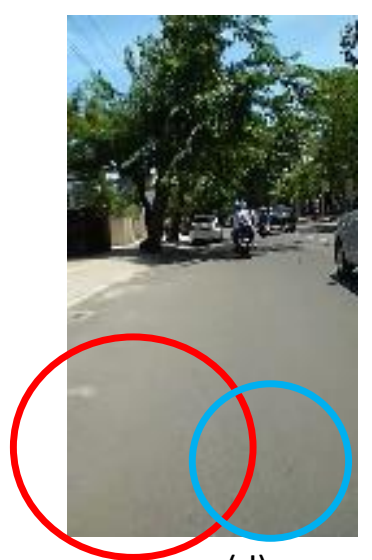

(d)

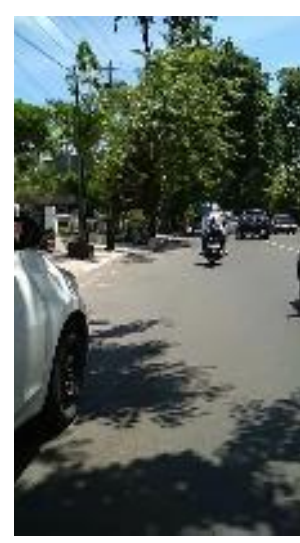

(e)

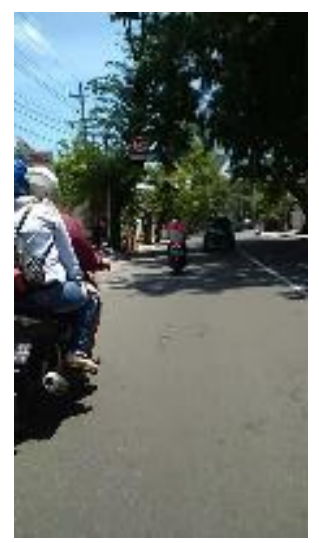

(f)

Figure 3. Differences between Raw data and Color magnification effect: a) b) c) effect after color magnification on sample; d) e) f) condition in raw data.

The computational analysis is performed by following three parameters, such: number of frames, frame rate, and height of pyramids. Based on experimental activity, the results can be listed in Table 1.

Table 1. Computational Result of Road Environment Color Magnification

\begin{tabular}{|c|c|c|c|}
\hline Video - th & Frame Rate & Number of Frames & Height of Pyramid \\
\hline 1 & 50 & 1,027 & 15 \\
\hline 2 & 50 & 843 & 15 \\
\hline 3 & 50 & 900 & 14 \\
\hline 4 & 48 & 750 & 14 \\
\hline 5 & 47 & 650 & 15 \\
\hline 6 & 50 & 787 & 15 \\
\hline 7 & 47 & 776 & 15 \\
\hline 8 & 50 & 1,004 & 15 \\
\hline 9 & 50 & 988 & 15 \\
\hline 10 & 48 & 980 & 15 \\
\hline
\end{tabular}

Although frame of each video has different number, the height of pyramid is quite consistent, it is just two videos has different height. The two videos just have onepoint difference with another video, so it does not interprete as an abberation.

Figure 4 shows PSNR result in each video by sample $50^{\text {th }}-550$ th frame. There is a unique phenomenon on this result, not all frame has same result condition, if pattern of results is examined it would be discovered that in example if some videos in certain frame has lower PSNR value, minimum one other video has upper value. One factor for sure to analyze this happening, different scene on video could result different color magnification and PSNR result. 


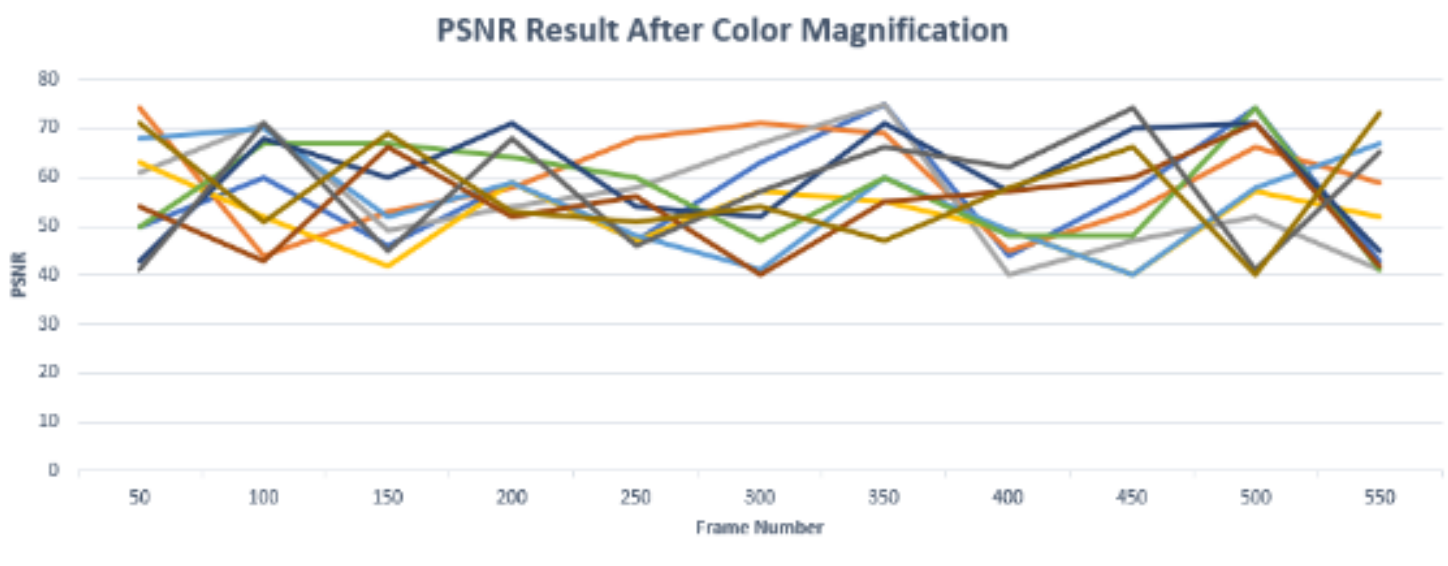

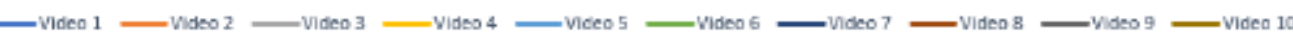

Figure 4. PSNR result on each video after color magnification by sample $50^{\text {th }}-550^{\text {th }}$ sample

More random value is shown by Figure 5 , it is different with figure $x x x$ which has similar pattern between each video. Figure 5 which represents SSIM result does not have clear pattern to be well-analyzed by its result value. The random occurs because color magnification makes variation of SSIM value, the similarity may differ because color magnification effect has intervened SSIM mapping.

SSIM Result After Color Magnification

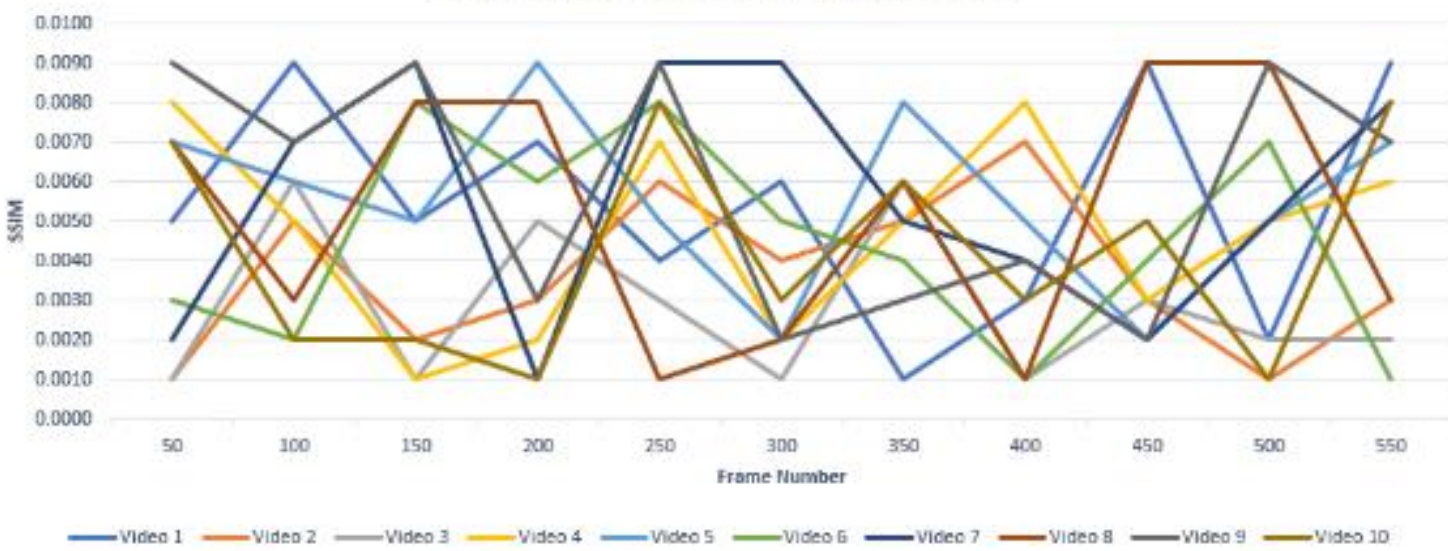
Figure 5. Random value of SSIM result on each video after color magnification by sample $50^{\text {th }}-550^{\text {th }}$
sample

\section{CONCLUSION}

Color magnification in vehicle on the road video is not easy because color magnification effect creates too many color appearances in road environment in video. So, many conditions can not be explained well because so many unpredicted phenomena like black color apparance domination in lower level of gray of road color happens visually. But, by this result, it can be some useful information to make those color be a feature to decide whether the best vehicle walk path in the road, although this study requires more analysis. PSNR gives quite stable value result although not all video has same pattern with another video. SSIM has more random results because color magnification has intervened SSIM mapping. In the future, we will analyze those color magnification results to be a usefule feature for safety vehicle autoamtic system. 


\section{ACKNOWLEDGMENT}

Authors would like to thank to Ministry of Research, Technology, and Higher Education (Kementerian Riset, Teknologi, dan Pendidikan Tinggi/ Kemenristekdikti) Republik Indonesia who supports and gives a funding for this research activity via Penelitian Dosen Pemula (PDP) Research Grant and also LPPM Universitas Dian Nuswantoro who gives supports and guidances.

\section{REFERENCES}

[1] Wu H.Y, Rubinstein M, Shih E, Guttag J, Durand F, Freeman W. Eulerian Video Magnification for Revealing Subtle Changes in the World. ACM Transactions on Graphics-Siggraph 2012. 2012.

[2] Wadhwa N, Rubinstein M, Shih E, Guttag J, Durand F, Freeman W. Phase-Based Video Motion Processing. ACM Transactions on Graphics-Siggraph 2013. 2013.

[3] Bernini, Nicola. Bertozzi, Masimo. Castangia, Luca. Patander, Marco. Sabbatelli, Mario. 2014. Real-time obstacle detection using stereo vision for autonomous ground vehicles: A survey. 2014 IEEE 17th International Conference on Intelligent Transportation Systems (ITSC). halaman 873-878.

[4] Komite Nasional Keselamatan Transportasi Kementrian Perhubungan Republik Indonesia. 2016. Data Investigasi Kecelakaan LLAJ Tahun 2010-2016.Jakarta.

[5] Korps Lalulintas Kepolisian Republik Indonesia. 2017. Kecelakaan di Indonesia selama triwulan terakhir.URL: http://www.korlantas-irsms.info/graph/accidentData?lang=id (accessed: 19 Juni 2017, 23: 11 WIB)

[6] Hui, Zu. Yaouhua, Xie. Lu, Ma. Jiansheng, Fu. 2014. Vision-based real-time traffic accident detection. Proceeding of the 11th World Congress on Intelligent Control and Automation. pages 1035-1038. Shenyang, China.

[7] Wang J, Drucker S.M, Agrawala M, Cohen M.F. The Cartoon Animation Filter. ACM Transactions on Graphics-Siggraph 2006. 2006. 25: 1169-1173.

[8] Liu C, Torralba A, Freeman W.T, Durand F, Adelson E.H. Motion Magnification. ACM Transaction on Graphics. 2005. 24: 512-526.

[9] Masilkova, Monika. 2017. Health and social consequences of road traffic accidents. Social Science in Health, Article in Press.

[10] Porada, V. 2000. Silnicni dopravni nehoda v teorii a praxi. Linde. Praha. 